Journal of Patient-Centered

\title{
Mobile Health Technology Knowledge and Practices Among Patients of Safety-Net Health Systems in Washington State and Washington, DC
}

Sharon S. Laing

Muhammad Alsayid

Carlota Ocampo

Stacey Baugh

Follow this and additional works at: https://aah.org/jpcrr

Part of the Health Information Technology Commons, Health Services Research Commons, and the Social and Behavioral Sciences Commons

\section{Recommended Citation}

Laing SS, Alsayid M, Ocampo C, Baugh S. Mobile health technology knowledge and practices among patients of safety-net health systems in Washington State and Washington, DC. J Patient Cent Res Rev. 2018;5:204-17. doi: 10.17294/2330-0698.1622

Published quarterly by Midwest-based health system Advocate Aurora Health and indexed in PubMed Central, the Journal of Patient-Centered Research and Reviews (JPCRR) is an open access, peer-reviewed medical journal focused on disseminating scholarly works devoted to improving patient-centered care practices, health outcomes, and the patient experience. 


\title{
Mobile Health Technology Knowledge and Practices Among Patients of Safety-Net Health Systems in Washington State and Washington, DC
}

\author{
Sharon S. Laing, PhD, , ${ }^{1,2}$ Muhammad Alsayid, MD, MPH, ${ }^{2,3}$ Carlota Ocampo, PhD, ${ }^{4}$ Stacey Baugh, $\mathrm{PsyD}^{4}$ \\ ${ }^{1}$ Nursing and Healthcare Leadership Program, University of Washington Tacoma, Tacoma, WA; ${ }^{2}$ Health Services \\ Department, University of Washington School of Public Health, Seattle, WA; ${ }^{3}$ Department of Medicine, University of \\ Massachusetts Medical School, Worcester, MA; ${ }^{4}$ Department of Psychology, Trinity Washington University, Washington, DC
}

Purpose Mobile health technology (mHealth) can reduce health disparities, but research on the health behaviors of low-income patients is needed. This study evaluates mHealth knowledge and practices of lowresource safety-net patients.

Methods We administered a 47-item questionnaire to 164 low-income patients accessing services at community health centers in the state of Washington and Washington, DC. Predictor variables included demographic factors: age, race, ethnicity, income. Outcome variables were smartphone knowledge (smartphones as a wellness tool), medical app knowledge (availability of medical-based apps), smartphone practices (ever used smartphones for wellness), health apps practices (ever used health-based apps), and medical apps practices (ever used medical-based apps). Multivariate logistic regression assessed relationships between predictor and outcome variables.

Results Mean age was 35.2 years (median: 34), and study cohort ( $\mathrm{N}=159)$ consisted of mostly women (68\%), white race (36\%), and income of $<\$ 20,000 /$ year (63\%). Outcomes: $71 \%$ and $58 \%$ reported knowledge of using smartphones for wellness and knowledge of medical apps, respectively; $76 \%$ used smartphones for wellness, with adults $50+$ years of age significantly less likely than younger adults (odds ratio [OR]: 0.94, $95 \%$ confidence interval [CI]: $0.88-0.99$ ); $48 \%$ used health apps, with adults $50+$ years of age less likely than younger adults (OR: $0.95,95 \% \mathrm{Cl}: 0.91-0.99)$ and respondents earning $<\$ 20,000 /$ year less likely than higher earners (OR: $3.13,95 \% \mathrm{Cl}: 1.02-9.57)$; and 58\% used medical apps, with Hispanics/ Latinos significantly more likely than non-Hispanics/Latinos (OR: 6.38, 95\% Cl: 1.04-39.02).

Conclusions Safety-net patients use mobile devices for health promotion. Age and income are important predictive factors, suggesting a more tailored design of the technology is required for broad engagement and health equity. (J Patient Cent Res Rev. 2018;5:204-217.)

Keywords knowledge; practices; safety-net patients; mobile health promotion; telehealth; smartphone

A recent roundtable discussion of health care and government leaders and health policy analysts concluded that hand-held devices, including smartphones, tablets, and mobile applications (apps), can improve patient-doctor relationships and thus improve health outcomes. ${ }^{1}$ For low-income communities

Correspondence: Sharon S. Laing, PhD,

University of Washington Tacoma, 1900 Commerce Street, Box 358421, Tacoma, WA 98402 (laings@uw.edu) disproportionately impacted by chronic diseases, potential benefits can be significantly impactful.

Mobile health technology (mHealth) is "medical and public health practices supported by mobile devices, such as mobile phones, patient monitoring devices, personal digital assistants and other wireless devices." ${ }^{2}$ Among the wireless technology used for mHealth interventions, short message service (SMS) and mobile health apps are deployed most frequently. Mobile health apps can promote self-care management 
and increase access to useful health information that supports wellness. ${ }^{3}$ Medical-based apps are mobile apps that "may transform a mobile platform into a regulated medical device" and include technologies that facilitate disease self-management, tools that organize and track a health condition, and devices that provide valuable health information. ${ }^{3}$ Apps, SMS, and wireless sensors are used with mobile phones to implement mobile health promotion.

Research studies demonstrate how mHealth can be used to effectively promote patient health care engagement. For preventive care, studies have shown moderate effects of SMS and mobile apps in supporting physical activity, ${ }^{4}$ increasing attendance at medical appointments, ${ }^{5}$ and improving smoking cessation at 6-month follow-up. ${ }^{6}$ Mobile health interventions also have helped with chronic disease management, with clinical studies reporting reductions in glycosylated hemoglobin levels ranging from $0.5 \%$ to $1.9 \%,{ }^{7-9}$ improved management of cardiovascular outcomes, ${ }^{10,11}$ and reductions in depressive symptomatology. ${ }^{12}$

Though research on the value of mHealth in promoting wellness continues to proliferate, the majority of these studies do not target the communities most affected by poor health outcomes - low-income individuals. To be sure, there is a growing subset of interventional studies addressing chronic disease management in low- and middle-income countries; ${ }^{13-16}$ however, within highincome countries such as the United States, there are few mHealth clinical studies specifically targeting low-income or safety-net patients (ie, patients served by community health centers $[\mathrm{CHCs}]$ ).

Low-income and safety-net patients present with substantial health challenges compared to the general population. And as revealed in a recent analysis, $\mathrm{CHC}$ patients in particular are poorer, report more chronic health conditions, have higher rates of obesity, and are more likely to be smokers than the overall lowincome U.S. population. ${ }^{17}$ Low-income communities present with the highest rates of diabetes prevalence and appear less likely to be referred for care for this health condition. ${ }^{18}$ Research also has revealed poverty to be a reliable social determinant of cardiovascular diseases, including elevated blood pressure. ${ }^{19}$ Growing clinical research has shown that both diabetes and cardiovascular diseases can be managed using mHealth interventions, ${ }^{7-10}$ thus demonstrating the potential value of mobile health technologies in improving patient health outcomes for low-income communities. Using mHealth approaches to increase outreach to the most vulnerable patients, wherever they are, can result in long-term benefits of better patient engagement and improved health outcomes.

In order to intervene with a given patient population, one must understand the cognitive and behavioral factors (knowledge and practices) of the target community so that customized health interventions can be developed. Although descriptive data on mHealth practices of the U.S. population in general and on specific demographics therein are available, ${ }^{20}$ to our knowledge, there are no inferential-level data that outline mHealth knowledge and practices of lowincome, safety-net patients in the United States. Such information could inform the development of tailored behavioral and policy-related mHealth strategies to support this community.

The objective of the current study is to evaluate mHealth knowledge and practices, and to identify the relevant sociodemographic predictors of these practices, among low-income patients accessing services at $\mathrm{CHCs}$ in two regions - the state of Washington and Washington, DC.

\section{METHODS \\ Setting and Sample}

The study team partnered with $5 \mathrm{CHC}$ sites in Washington State and Washington, DC, to sample a total of 164 respondents. In western Washington, 103 patients were randomly selected from HealthPoint CHCs. HealthPoint is a regional community-supported and not-for-profit health system that offers comprehensive and coordinated health care services such as medical, dental, naturopathic, behavioral health, social services, and case management care. We partnered with HealthPoint because of the institution's history of providing health services to lowincome, racially diverse, and underserved communities. Further, HealthPoint centers are scattered throughout the northern region of western Washington, and the residents in that region are racially and ethnically diverse.

In Washington, DC, patients comprised a convenience sample of 61 patients from 3 community and human services centers. The centers offer community health 
care, human services support, case management/ coordination services, sexually transmitted disease testing, and support care to clients. The range of individuals seen includes the marginalized and underserved: members of the bilingual LGBT community; low-income women and girls of color living with or at risk for HIV/AIDS; and substanceabusing individuals.

All study procedures and protocols were approved by the institutional review boards of HealthPoint (Renton, WA), Eastern Washington University (Cheney, WA), and Trinity Washington University (Washington, DC).

\section{Instrument}

We used a 47-item instrument of mostly closed-ended questions to evaluate the knowledge and practices of CHC patients. The survey was available in both English and Spanish to support majority populations served by the CHCs. The instrument assessed patients' practice/use of mobile health technology (smartphones and health-based mobile apps) and perceptions of health care services received. Three sections comprised the survey. Section A presented 9 items addressing demographic characteristics including age, gender, race, education, employment status, and income. Section B presented 18 items that queried respondents about 1) general knowledge/awareness of mobile devices; 2) mobile device ownership, including medical and health-based mobile apps; and 3 ) use frequency of mobile health devices. Section $\mathrm{C}$ consisted of 20 questions that queried respondents about health-related experiences, including types of services received, availability of and accessibility to health care resources, chronic disease prevention support, and health care delivery satisfaction.

\section{Survey Administration}

The authors commenced survey administration in September 2014 and concluded in November 2015. The initial contact with patients varied slightly at the two sites. In Washington, DC, patients were informed about the study by staff and given the option to come to the centers on the days that investigators were administering questionnaires. In Washington State, investigators approached each person who entered the waiting area of the facility. (Figure 1 shows recruitment schema for both sites.) After initiating contact, researchers at both sites informed prospective participants that the purpose of the survey was to understand patients' knowledge/awareness and practice/use of mobile health technology and to learn about their perception of care at the health care facility.

To be included in the study, the prospective respondent must have 1) been in possession of a smartphone; 2) reached 18 years of age; and 3) had at least two face-to-face contacts with a professional at the center within the last 12 months. The patients at both sites who agreed to participate in the study and who met the eligibility criteria were taken to a private room where they completed a written informed consent document followed by the 47-item self-administered questionnaire, after which, researchers remained in the room to answer questions. At the conclusion, each participant received a $\$ 10$ gift certificate, was debriefed about the study, and had all questions answered. The entire process, including obtaining consent, survey administration, and debriefing lasted approximately 1 hour for each patient.

\section{Measured Variables: Knowledge/Awareness Factors}

To assess knowledge/awareness of mobile health technology, investigators queried respondents about level of awareness of two categories of mobile health technology: the capability of smartphones to provide wellness information; and the availability of mobile health apps to support health care management (ie, medical-based apps).

Smartphone Use for Wellness: Respondents were required to answer yes or no to the following statement, "Some people use smartphones/mobile devices as part of patient wellness, prevention, and treatment programs. For example, patients can go on the internet to get medical information about their health including going to such sites as WebMD, MDadvice, MedicineNet and NetDoctor. Were you aware that you can use your smartphones as part of your health care and wellness plan?"

Medical-Based Apps to Support Clinical/Health Care Management: To assess patients' awareness of specific mobile apps that support patient clinical and health care management, respondents were required to answer 

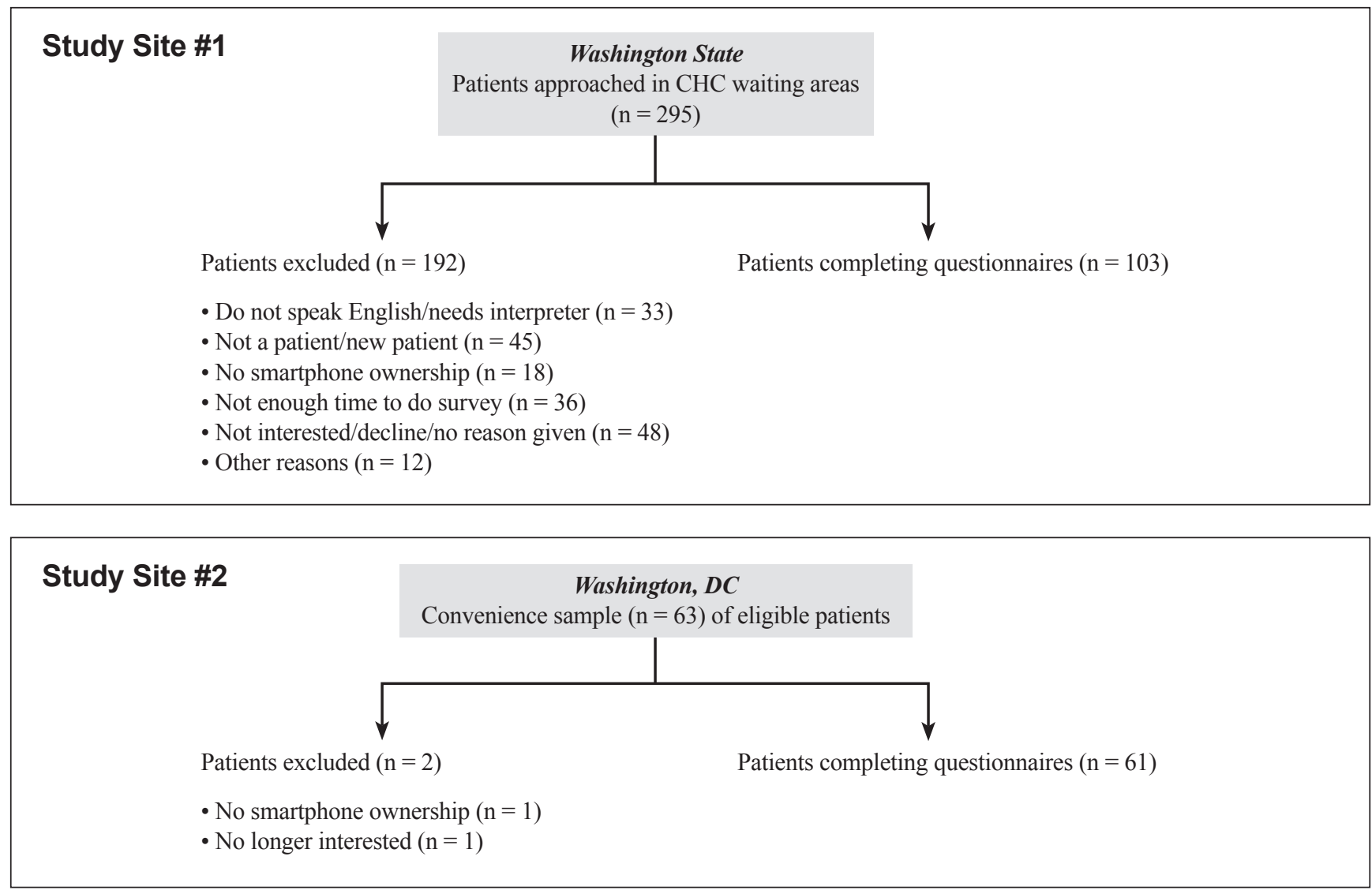

Figure 1. Recruitment of patients from community health centers (CHC) in Washington State and Washington, DC, 2014-2015.

yes or no to the following statement, "Some mobile applications are medical-based - that is, they help to promote health by reminding patients to take medications and helping patients to refill their prescriptions. Were you aware that such applications are available?"

\section{Measured Variables: Practice/Use Factors}

Mobile health technology practices were defined as 1) using smartphones for wellness; 2) using medicalbased mobile apps; and 3) using health-based apps. Investigators queried patients with specific question(s) targeting each category.

Using Smartphone for Wellness: To assess patients' use of smartphones for health and wellness, researchers asked respondents two questions: 1) "Have you ever used your smartphone or a mobile device to get information about your health or as part of a wellness plan?" Patients were required to give a yes or no response. 2) "If you have used your smartphone/ mobile device to access health information, how often would you say you've used it this way?" Patients were given the following choices: one or more times daily, one or more times each week, one or more times each month, less than every few months, and never used smartphones in this way. Respondents were designated as "users" of smartphone for wellness if they answered affirmatively to the first question and/or identified a frequency of using their smartphones for wellness.

Using Medical-Based Mobile Apps: To assess patients' use of medical-based apps, investigators posed two questions to patient respondents: 1) "Have you ever used mobile applications for any of the medical purposes described?" Patients were required to give a yes or no response. 2) "Please indicate which among the following medical-based ways you have used your mobile applications." Choices included locate pharmacist/doctor, prescription refill, medication reminders, tracking heart rate, tracking blood pressure, 
and tracking blood glucose. Respondents were designated "users" of medical-based mobile apps if they answered affirmatively to the first question and/or specified an app that they currently owned.

Using Health-Based Apps: We defined a health-based app as a mobile application for preventive health care, including tracking caloric intake or engagement in meditation/relaxation. To assess patients' use of health-based apps, two questions were posed: 1) "Have you ever used a health-based mobile application?" Patients were required to give a yes or no response. 2) "What type of health app do you have?" Respondents were provided with choices: calorie count, step count, smoking cessation, meditation/relaxation, and other health apps. Respondents were designated "users" of health-based mobile apps if they answered affirmatively to the first question and/or indicated an app currently owned.

\section{Statistical Analyses}

Descriptive analyses were conducted to describe demographic characteristics of the full sample as well as site-specific respondent characteristics (DC and Washington State). Demographics analyzed included gender (male or female), age (categorized as 18-29, $30-49$, and $\geq 50$ years of age), and race (white, African American, Asian, American Indian, Alaska Natives, Mixed White Indigenous, Native Hawaiians, Pacific Islanders, and other). A separate racial category, "multiple races" combined the last six racial groups due to low numbers in each race category; thus, four race categories were analyzed - White, African American, Multiple Races, and Other. Ethnicity was defined as identification as Hispanic/Latino ethnicity or nonHispanic/Latino. Employment was defined as full-time employment, part-time employment, unemployed, and not working/not looking; the "not looking" category referred to individuals in school, retirees, disabled individuals, or homemakers. Income was defined as less than or equal to $\$ 20,000 /$ year or more than $\$ 20,000 /$ year. Education was defined as high schooleducated or higher or less than high school-educated. We assessed differences in demographic characteristics between the two study sites using chi-squared analyses and reported P-values for each demographic factor.

Descriptive analysis was used to identify raw counts and proportions of "yes" responses for each knowledge factor (knowledge of using smartphone for wellness, knowledge of medical-based apps) by the relevant demographic groups. The same approach was used to describe the practice factors (use of smartphone for wellness, use of health-based apps, use of medicalbased apps). Finally, we reported proportions for the following: frequency of using smartphone for wellness, types of health apps owned, and types of medical apps owned.

Multivariate logistic regression analyses were performed to assess the association between each factor (for knowledge and practice) and demographic characteristics. The models consisted of all relevant demographic factors with odds ratios (OR) reported for 95\% confidence intervals. Data were analyzed using STATA/IC Version 14.2 (StataCorp LLC, College Station, TX).

\section{RESULTS}

\section{Description of Full Sample}

Response rate of patients who were approached in the CHCs in Washington State was 35\%. Among the 295 patients approached, only 18 indicated nonownership of smartphones, thus $94 \%$ of patients were smartphone owners (Figure 1). Due to substantial missing data for 5 respondents, data were analyzed for 159 respondents. The mean age of this cohort was 35.2 years (standard deviation: 12.24) and ranged from 18 to 81 years. The sample comprised mostly of women (68\%), adults age $30-49$ years (52\%), Whites or African Americans (36\% and $31 \%$, respectively), income below $\$ 20,000 /$ year (63\%), and higher than high school-level education (53\%).

Table 1 shows the comparison between Washington State and Washington, DC, sites. All sociodemographic characteristics were similar for both sites, except for race, employment status, and household income. At the DC site, there were significantly more African American respondents ( $57 \%$ vs $18 \%, \mathrm{P}<0.01)$, patients reporting being unemployed ( $40 \%$ vs $16 \%, \mathrm{P}<0.01$ ), and individuals earning less than $\$ 20,000 /$ year $(82 \%$ vs $52 \%, \mathrm{P}<0.01)$.

\section{Knowledge/Awareness Factors}

As seen in Table 2, 71\% of CHC patients were aware that smartphones can be used to access health information and $58 \%$ knew about the availability of medical-based apps. 
Table 1. Sociodemographic Characteristics of Study Participants by Site of the Community Health Centers, 2014-2015

\begin{tabular}{|c|c|c|c|c|}
\hline Demographic characteristic & $\begin{array}{c}\text { Total cohort } \\
(\mathrm{N}=159)\end{array}$ & $\begin{array}{c}\text { Washington State } \\
(n=103)\end{array}$ & $\begin{array}{c}\text { Washington, DC } \\
(n=56)\end{array}$ & $P$ \\
\hline Gender, n (\%) & & & & 0.61 \\
\hline Male & $50(31.6)$ & $34(33.0)$ & $16(29.1)$ & \\
\hline Female & $108(68.4)$ & $69(67.0)$ & $39(70.9)$ & \\
\hline Age bracket, $\mathrm{n}(\%)$ & & & & 0.88 \\
\hline $18-29$ years & $54(34.2)$ & $36(35.0)$ & $18(32.7)$ & \\
\hline $30-49$ years & $82(51.9)$ & $52(50.5)$ & $30(54.5)$ & \\
\hline $50+$ years & $22(13.9)$ & $15(14.5)$ & $7(12.7)$ & \\
\hline Mean age, years (SD) & $35.2(16.2)$ & $36.5(12.6)$ & $32.8(21.3)$ & \\
\hline Median age, years (IQR) & $34(27,45)$ & $37(26,46)$ & $33(27,42)$ & \\
\hline Race, n (\%) & & & & $<0.01$ \\
\hline White & $53(36.1)$ & $49(51.0)$ & $4(7.8)$ & \\
\hline African American & $46(31.3)$ & $17(17.7)$ & $29(56.9)$ & \\
\hline Multiple Races* & $15(10.2)$ & $7(7.3)$ & $8(15.7)$ & \\
\hline Other (not specified) & $33(22.4)$ & $23(24.0)$ & $10(19.6)$ & \\
\hline Ethnicity, n (\%) & & & & 0.17 \\
\hline Hispanic/Latino & $40(26.8)$ & $22(23.2)$ & $18(33.3)$ & \\
\hline Non-Hispanic/Latino & $109(73.2)$ & $73(76.8)$ & $36(66.7)$ & \\
\hline Employment, n (\%) & & & & $<0.01$ \\
\hline Full-time & $41(28.1)$ & $31(31.3)$ & $10(21.3)$ & \\
\hline Part-time & $37(25.3)$ & $25(25.3)$ & $12(25.5)$ & \\
\hline Unemployed & $35(24.0)$ & $16(16.2)$ & $19(40.4)$ & \\
\hline Retired/homemaker/not looking for work & $33(22.6)$ & $27(27.3)$ & $6(12.8)$ & \\
\hline Household income,$^{\dagger} \mathrm{n}(\%)$ & & & & $<0.01$ \\
\hline At or below $\$ 20,000 /$ year & $89(62.7)$ & $47(51.6)$ & $42(82.4)$ & \\
\hline More than $\$ 20,000 /$ year & $53(37.3)$ & $44(48.4)$ & $9(17.6)$ & \\
\hline Education, n (\%) & & & & 0.27 \\
\hline High school or less & $74(46.8)$ & $45(43.7)$ & $29(52.7)$ & \\
\hline Higher than high school & $84(53.2)$ & $58(56.3)$ & $26(47.3)$ & \\
\hline
\end{tabular}

*Includes Asians, American Indians, Alaska Natives, Mixed White Indigenous, Native Hawaiians, and Pacific Islanders. Due to small counts in each race, the group "Multiple Races" was created.

tIncome less than $\$ 20,000 /$ year represented the U.S. Department of Health and Human Services Federal Poverty Level guideline for a 3-member household.

Bold indicates significant at the $P<0.05$ level. $I Q R$, interquartile range; $S D$, standard deviation.

Knowledge of Smartphone for Wellness: The primary demographic characteristics of patients who reported having an awareness of smartphones to acquire wellness information were female gender ( $72 \%$ ), age $30-49$ years (74\%), White race $(72 \%)$, Hispanic/Latino ethnicity (70\%), high school education or higher (74\%), income more than \$20,000/year (75\%), and employment part-time (87\%) (Table 2). None of the demographic factors emerged as a significant independent predictor of knowledge of smartphone for wellness in the multivariate regression analysis (Table 5).

Knowledge of Medical Apps: Dominant demographic characteristics of the sample reporting an awareness of medical app were female gender (66\%), age 18-49 years (60\%), African American and Multiple Races 
Table 2. Mobile Health Technology Knowledge of Community Health Center Patients by Demographic Factors, 2014-2015

\begin{tabular}{|c|c|c|}
\hline Demographic characteristic & $\begin{array}{c}\text { Knowledge of } \\
\text { smartphone use } \\
\text { for wellness }\end{array}$ & $\begin{array}{l}\text { Knowledge of } \\
\text { medical apps }\end{array}$ \\
\hline Total study cohort, n (\%) & $110(71.0)^{\dagger}$ & $91(58.0)$ \\
\hline \multicolumn{3}{|l|}{ Gender, n (\%) } \\
\hline Male & $33(68.8)$ & $19(39.6)$ \\
\hline Female & $76(71.7)$ & $71(65.7)$ \\
\hline \multicolumn{3}{|l|}{ Age bracket, n (\%) } \\
\hline $18-29$ years & $34(68.0)$ & $32(60.4)$ \\
\hline $30-49$ years & $61(74.4)$ & $49(60.5)$ \\
\hline 50 years and above & $14(63.6)$ & $9(40.9)$ \\
\hline \multicolumn{3}{|l|}{ Race, n (\%) } \\
\hline White & $38(71.7)$ & $25(47.2)$ \\
\hline African American & $31(68.9)$ & $31(67.4)$ \\
\hline Multiple Races* & $10(73.3)$ & $10(66.7)$ \\
\hline Other (not specified) & $23(69.7)$ & $17(53.1)$ \\
\hline \multicolumn{3}{|l|}{ Ethnicity, n (\%) } \\
\hline Hispanic/Latino & $26(70.3)$ & $26(66.7)$ \\
\hline Non-Hispanic/Latino & $74(68.5)$ & $60(55.6)$ \\
\hline \multicolumn{3}{|l|}{ Education, n (\%) } \\
\hline High school or less & $48(67.6)$ & $40(55.6)$ \\
\hline Higher than high school & $62(73.8)$ & $50(59.5)$ \\
\hline \multicolumn{3}{|l|}{ Household income, n (\%) } \\
\hline$<\$ 20,000$ & $62(70.5)$ & $49(55.1)$ \\
\hline$\$ 20,000$ and above & $39(75.0)$ & $30(57.7)$ \\
\hline \multicolumn{3}{|l|}{ Employment status, n (\%) } \\
\hline Full-time & $29(72.5)$ & $20(50.0)$ \\
\hline Part-time & $32(86.5)$ & $24(64.9)$ \\
\hline Unemployed & $21(61.8)$ & $19(54.3)$ \\
\hline Retired/homemaker/not looking for work & $18(56.3)$ & $19(59.4)$ \\
\hline \multicolumn{3}{|l|}{ Location, n (\%) } \\
\hline Washington State & $74(72.5)$ & $49(48.5)$ \\
\hline Washington, DC & $36(67.9)$ & $42(75.0)$ \\
\hline
\end{tabular}

*Includes Asians, American Indians, Alaska Natives, Mixed White Indigenous, Native Hawaiians, and Pacific Islanders. Due to small counts in each race, the group "Multiple Races" was created.

tIndicates 110 of $155=71 \%$. Due to missing data in total respondents for "use" variable, the study reported a higher proportion for "use of smartphone for wellness" compared to "knowledge of smartphone for wellness."

race (67\%), Hispanic/Latino ethnicity (67\%), high school education or higher $(60 \%)$, income more than $\$ 20,000$ / year (58\%), and part-time employment (65\%) (Table 2). Multivariate logistic regression analysis of demographic predictors revealed that only gender, age, and study site were significant unique contributors to knowledge of medical-based apps. Women were significantly more likely than men to report an awareness of medicalbased apps when all other demographic predictors were adjusted (OR: 3.52, 95\% CI: 1.35-9.20). Adults 50 or more years old were significantly less likely to indicate an awareness of medical-based apps compared to adults 
Table 3. Mobile Health Technology Practices of Community Health Center Patients by Demographic Factors, 2014-2015

\begin{tabular}{|c|c|c|c|}
\hline Demographic characteristic & $\begin{array}{c}\text { Ever use smartphone } \\
\text { for wellness }\end{array}$ & $\begin{array}{c}\text { Ever use medical- } \\
\text { based apps }\end{array}$ & $\begin{array}{c}\text { Ever use } \\
\text { health apps }\end{array}$ \\
\hline Total study cohort, n (\%) & $103(76.3)^{\dagger}$ & $64(58.2)$ & $72(48.3)$ \\
\hline \multicolumn{4}{|l|}{ Gender, n (\%) } \\
\hline Male & $28(70.0)$ & $13(48.1)$ & $19(38.8)$ \\
\hline Female & $74(78.7)$ & $50(61.0)$ & $52(52.5)$ \\
\hline \multicolumn{4}{|l|}{ Age bracket, $\mathrm{n}(\%)$} \\
\hline $18-29$ years & $36(83.7)$ & $16(48.5)$ & $26(52.0)$ \\
\hline $30-49$ years & $55(76.4)$ & $41(67.2)$ & $42(53.8)$ \\
\hline$\geq 50$ years & $11(57.9)$ & $6(40.0)$ & $4(19.0)$ \\
\hline \multicolumn{4}{|l|}{ Race, n (\%) } \\
\hline White & $36(87.8)$ & $18(58.1)$ & $25(50.0)$ \\
\hline African American & $30(69.8)$ & $21(58.3)$ & $17(41.5)$ \\
\hline Multiple Races* & $10(71.4)$ & $6(50.0)$ & $5(38.5)$ \\
\hline Other (not specified) & $18(66.7)$ & $11(50.0)$ & $16(48.5)$ \\
\hline \multicolumn{4}{|l|}{ Ethnicity, n (\%) } \\
\hline Hispanic/Latino & $27(81.8)$ & $22(75.9)$ & $20(57.1)$ \\
\hline Non-Hispanic/Latino & $67(72.8)$ & $38(51.4)$ & $46(43.8)$ \\
\hline \multicolumn{4}{|l|}{ Education, n (\%) } \\
\hline High school or less & $46(75.4)$ & $29(56.9)$ & $31(47.0)$ \\
\hline Higher than high school & $56(76.7)$ & $34(58.6)$ & $40(48.8)$ \\
\hline \multicolumn{4}{|l|}{ Household income, n (\%) } \\
\hline$<\$ 20,000$ & $56(71.8)$ & $33(55.0)$ & $35(42.7)$ \\
\hline$\geq \$ 20,000$ & $35(79.5)$ & $23(62.2)$ & $28(53.8)$ \\
\hline \multicolumn{4}{|l|}{ Employment status, n (\%) } \\
\hline Full-time & $28(82.4)$ & $14(60.9)$ & $20(50.0)$ \\
\hline Part-time & $25(71.4)$ & $13(44.8)$ & $19(54.3)$ \\
\hline Unemployed & $23(74.2)$ & $15(60.0)$ & $14(46.7)$ \\
\hline Retired/homemaker/not looking for work & $18(81.8)$ & $15(68.2)$ & $13(40.6)$ \\
\hline \multicolumn{4}{|l|}{ Location, n (\%) } \\
\hline Washington State & $67(82.7)$ & $34(54.0)$ & $47(46.5)$ \\
\hline Washington, DC & $36(66.7)$ & $30(63.8)$ & $25(52.1)$ \\
\hline
\end{tabular}

*Includes Asians, American Indians, Alaska Natives, Mixed White Indigenous, Native Hawaiians, and Pacific Islanders. Due to small counts in each race, the group "Multiple Races" was created.

tIndicates 103 of $135=76 \%$. Due to missing data in total respondents for the "use" variable, the study reported a higher proportion for "use of smartphone for wellness" compared to "knowledge of smartphone for wellness."

18-49 years old (OR: 0.95, 95\% CI: 0.91-0.99). Finally, CHC patients in Washington, DC, were significantly more likely to report an awareness of medical-based apps compared to CHC patients residing in Washington State (OR: 3.77, 95\% CI: 1.09-13.01). No other demographic factors significantly predicted awareness of medicalbased mobile apps (Table 5).

\section{Practice/Use Factors}

Table 3 presents the three practice/use factors: use of smartphone for wellness, use of health-based apps, and use of medical-based apps. More than three-quarters (76\%) of respondents reported using smartphones for wellness; more than one-half (58\%) reported using medical-based apps; and 48\% used health-based apps 
including apps that track caloric intake and apps that track number of steps taken.

Use of Smartphone for Wellness: The demographic characteristics of individuals reporting use of smartphone to acquire wellness information resulted in mostly female gender (79\%), age 18-29 years $(84 \%)$, White race (88\%), Hispanic/Latino ethnicity (82\%), high school education or higher (77\%), income more than $\$ 20,000 /$ year ( $80 \%)$, and full-time employment (82\%) (Table 3). Furthermore, as shown in Table 4, 34\% used smartphones for wellness on a weekly basis. Another $16 \%$ of respondents reported never using smartphones to access wellness information. Multivariate logistic regression analysis revealed age and employment status to be unique and significant predictors of using smartphone for wellness. Adults 50 or more years old were significantly less likely to use their smartphones for wellness (OR: 0.94, 95\% CI: 0.88-0.99). Patients

Table 4. Frequency of Health Apps Used and Medical Apps Owned by Community Health Center Patients, 2014-2015

\begin{tabular}{lc}
\hline Use of Smartphone for Wellness & $\mathbf{n}(\%)$ \\
\hline Frequency of using smartphones for wellness & \\
1 or more times daily & $19(15.9)$ \\
1 or more times weekly & $40(33.6)$ \\
1 or more times each month & $33(27.7)$ \\
Less than every few months & $11(9.2)$ \\
Never used smartphones this way & $16(13.4)$ \\
\hline Use of Health Apps & $\mathbf{n ~ ( \% )}$ \\
\hline Types of health apps owned & \\
Calorie count & $37(37.8)$ \\
Step count & $27(27.6)$ \\
Meditation & $24(24.5)$ \\
Other & $24(24.7)$ \\
Smoking cessation & $6(6.1)$ \\
Don't own a health app & $34(37.4)$ \\
\hline Use of Medical-Based Apps & $\mathbf{n}(\%)$ \\
\hline Types of medical apps owned & $37(57.8)$ \\
Doctor/pharmacist locator & $36(56.3)$ \\
Prescription refill & $22(34.4)$ \\
Medication reminder & $20(31.3)$ \\
Track other health condition (not specified) & $17(26.6)$ \\
Family support & $13(20.3)$ \\
Heart rate tracker & $13(20.3)$ \\
Blood pressure tracker & $10(15.6)$ \\
Mental health status tracker & $6(9.4)$ \\
Blood glucose tracker & \\
\hline
\end{tabular}

who reported working part-time also were significantly less likely to indicate using smartphones for wellness compared to patients who worked full-time (OR: 0.17, 95\% CI: 0.03-0.83). No other demographic factor significantly predicted patients' use of smartphone for wellness (Table 5).

\section{Use and Ownership of Health-Based Mobile Apps:}

The dominant demographic characteristics of patients who reported using health-based apps were female gender (53\%), age 30-49 years (54\%), White race (50\%), Hispanic/Latino ethnicity (57\%), high school education or higher (49\%), income more than $\$ 20,000$ / year (54\%), and part-time employment (54\%) (Table 3).

As evident in Table 4, the health-based apps that CHC patients were likely to report owning included calorietracking (38\%), step-monitoring (28\%), and meditation apps $(25 \%)$. Patients were least likely to report owning apps that target smoking cessation (6\%). More than onethird $(37 \%)$ reported that they do not own a health app.

Multivariate logistic regression analysis revealed age and income to be significant independent predictors of patients' using health-based mobile apps (Table 5). Adults 50 or more years old were less likely to report ever using health apps (OR: 0.95, 95\% CI: 0.910.99). Patients earning more than $\$ 20,000 /$ year were significantly more likely to report using health-based mobile apps compared to patients earning less than \$20,000/year, (OR: 3.13, 95\% CI: 1.02-9.57).

\section{Use and Ownership of Medical-Based Mobile} Apps: The dominant demographic characteristics of respondents who reported using medical-based apps were female gender (61\%), age 30-49 years (67\%), African American and White race (58\%), Hispanic/ Latino ethnicity (76\%), high school education or higher (59\%), income more than $\$ 20,000 /$ year $(62 \%)$, and retirees/homemakers/not looking for work employment status (68\%) (Table 3). The medical-based apps that patients were likely to report owning were doctor/ pharmacist locator (58\%) and prescription refill (56\%) and medication (34\%) reminders (Table 4).

Multivariate logistic regression analysis of demographic factors revealed ethnicity to be the only significant independent predictor of patients using medical-based 
Table 5. Multivariate Logistic Regression — Demographic Factors Are Predictor Variables; Mobile Technology Knowledge and Practice Factors Are Outcome Variables

\begin{tabular}{|c|c|c|}
\hline Variable & Odds ratio & $95 \% \mathrm{Cl}$ \\
\hline \multicolumn{3}{|c|}{ Knowledge - awareness of using smartphone for wellness } \\
\hline Age & 0.99 & $0.95,1.03$ \\
\hline Study site (ref: WA) & 0.70 & $0.21,2.28$ \\
\hline Gender (ref: male) & 2.56 & $0.96,6.85$ \\
\hline Education (ref: high school or less) & 1.26 & $0.48,3.31$ \\
\hline Income (ref: $<\$ 20,000 /$ year) & 1.45 & $0.47,4.44$ \\
\hline \multicolumn{3}{|l|}{ Employment (ref: full-time) } \\
\hline Part-time employment & 4.11 & $0.90,18.84$ \\
\hline Unemployment & 0.63 & $0.18,2.27$ \\
\hline Retired/homemaker/not looking & 0.49 & $0.14,1.70$ \\
\hline \multicolumn{3}{|l|}{ Ethnicity } \\
\hline Hispanic/Latino & 1.07 & $0.29,3.90$ \\
\hline \multicolumn{3}{|l|}{ Race (ref: White) } \\
\hline African American & 0.84 & $0.22,3.13$ \\
\hline Multiple Races & 0.99 & $0.17,5.64$ \\
\hline Other & 1.14 & $0.29,4.41$ \\
\hline \multicolumn{3}{|c|}{ Knowledge - awareness of medical-based apps } \\
\hline Age & 0.95 & $0.91,0.99$ \\
\hline Study site (ref: WA) & 3.77 & $1.09,13.01$ \\
\hline Gender (ref: male) & 3.53 & $1.35,9.20$ \\
\hline Education (ref: high school or less) & 1.38 & $0.52,3.66$ \\
\hline Income (ref: $<\$ 20,000 /$ year) & 2.55 & $0.83,7.78$ \\
\hline \multicolumn{3}{|l|}{ Employment (ref: full-time) } \\
\hline Part-time employment & 2.57 & $0.70,9.49$ \\
\hline Unemployment & 0.75 & $0.19,2.93$ \\
\hline Retired/homemaker/not looking & 2.01 & $0.55,7.38$ \\
\hline \multicolumn{3}{|l|}{ Ethnicity } \\
\hline Hispanic/Latino & 1.49 & $0.41,5.41$ \\
\hline \multicolumn{3}{|l|}{ Race (ref: White) } \\
\hline African American & 2.78 & $0.72,10.74$ \\
\hline Multiple Races & 1.30 & $0.26,6.42$ \\
\hline Other & 0.91 & $0.24,3.39$ \\
\hline \multicolumn{3}{|l|}{ Practice - use of smartphone for wellness } \\
\hline Age & 0.94 & $0.88,0.99$ \\
\hline Study site (ref: WA) & 0.39 & $0.10,1.49$ \\
\hline Gender (ref: male) & 1.63 & $0.47,5.66$ \\
\hline Education (ref: high school or less) & 0.70 & $0.22,2.27$ \\
\hline Income (ref: $<\$ 20,000 /$ year) & 1.33 & $0.31,5.78$ \\
\hline \multicolumn{3}{|l|}{ Employment (ref: full-time) } \\
\hline Part-time employment & 0.17 & $0.03,0.83$ \\
\hline Unemployment & 0.25 & $0.05,1.37$ \\
\hline Retired/homemaker/not looking & 0.64 & $0.09,4.47$ \\
\hline \multicolumn{3}{|l|}{ Ethnicity } \\
\hline Hispanic/Latino & 1.19 & $0.22,6.35$ \\
\hline \multicolumn{3}{|l|}{ Race (ref: White) } \\
\hline African American & 0.65 & $0.12,3.57$ \\
\hline Multiple Races & 0.42 & $0.05,3.45$ \\
\hline Other & 0.29 & $0.05,1.70$ \\
\hline
\end{tabular}


Table 5 (continued). Multivariate Logistic Regression - Demographic Factors Are Predictor Variables; Mobile Technology Knowledge and Practice Factors Are Outcome Variables

\begin{tabular}{|c|c|c|}
\hline Variable & Odds ratio & $95 \% \mathrm{Cl}$ \\
\hline \multicolumn{3}{|l|}{ Practice - use of health apps } \\
\hline Age & 0.95 & $0.91,0.99$ \\
\hline Study site (ref: WA) & 1.93 & $0.59,6.33$ \\
\hline Gender (ref: male) & 2.55 & $0.97,6.73$ \\
\hline Education (ref: high school or less) & 0.83 & $0.33,2.10$ \\
\hline Income (ref: $<\$ 20,000 /$ year) & 3.13 & $1.02,9.57$ \\
\hline \multicolumn{3}{|l|}{ Employment (ref: full-time) } \\
\hline Part-time employment & 1.24 & $0.36,4.27$ \\
\hline Unemployment & 0.69 & $0.19,2.51$ \\
\hline Retired/homemaker/not looking & 0.44 & $0.12,1.62$ \\
\hline \multicolumn{3}{|l|}{ Ethnicity } \\
\hline Hispanic/Latino & 0.76 & $0.21,2.72$ \\
\hline \multicolumn{3}{|l|}{ Race (ref: White) } \\
\hline African American & 0.52 & $0.14,2.00$ \\
\hline Multiple Races & 0.22 & $0.04,1.28$ \\
\hline Other & 0.90 & $0.25,3.25$ \\
\hline \multicolumn{3}{|l|}{ Practice - use of medical-based apps } \\
\hline Age & 0.99 & $0.96,1.02$ \\
\hline Study site (ref: WA) & 0.57 & $0.13,2.47$ \\
\hline Gender (ref: male) & 2.46 & $0.68,8.98$ \\
\hline Education (ref: high school or less) & 0.76 & $0.24,2.39$ \\
\hline Income (ref: $<\$ 20,000 /$ year) & 1.95 & $0.46,8.37$ \\
\hline \multicolumn{3}{|l|}{ Employment (ref: full-time) } \\
\hline Part-time employment & 0.61 & $0.13,2.91$ \\
\hline Unemployment & 0.77 & $0.15,4.06$ \\
\hline Retired/homemaker/not looking & 1.29 & $0.23,7.35$ \\
\hline \multicolumn{3}{|l|}{ Ethnicity } \\
\hline Hispanic/Latino & 6.38 & $1.04,39.02$ \\
\hline \multicolumn{3}{|l|}{ Race (ref: White) } \\
\hline African American & 1.78 & $0.33,9.78$ \\
\hline Multiple Races & 0.51 & $0.08,3.39$ \\
\hline Other & 0.24 & $0.04,1.37$ \\
\hline
\end{tabular}

Bold indicates significant at the $P<0.05$ level.

$\mathrm{Cl}$, confidence interval; ref, reference; WA, state of Washington.

apps. Hispanic/Latino adults were significantly more likely than those who did not indicate Hispanic/Latino ethnicity to report ever using medical-based mobile apps (OR: 6.33, 95\% CI: 1.04-39.02).

\section{DISCUSSION}

A recent Blue Shield of California Foundation survey identified four keys to improve the health care experiences of low-income patients: continuity of care; connectedness between patients, care providers, and staff; feeling empowered to address health care needs; and having clear and understandable information to promote engagement. ${ }^{21}$ For too long, low-income communities have lacked resources to meaningfully engage in their health care and thus feel connected to the health care system. Mobile health technologies like smartphones and health apps are widely accessible and relatively inexpensive tools that may potentially provide substantial support to lower-income patients who access health services through CHCs. 
Our study demonstrated that mobile health technologies can be an effective tool for promoting health and wellness to safety-net patients and potentially provide continuity of care outside of clinic visits. Findings revealed strong awareness and past use of mobile health technologies to manage health and promote wellness. Further, a majority of safety-net patients report ownership of preventive care mobile health apps that target physical activity and weight management, and this result has favorable implications for managing the more prominent health risks (sedentary behavior, obesity) for the chronic diseases most prevalent in this community (diabetes, cardiovascular diseases). We identified specific demographics within the safety-net community likely to use health- and medical-based apps. Also noteworthy, however, are the safety-net demographics for whom mHealth tools might currently fall short and for whom more work is required to ensure engagement - the poorest safety-net patients and older-adult patient groups.

\section{Engaging Lowest-Income Safety-Net Patients}

Among safety-net patients, those with the lowest incomes $(<\$ 20,000 /$ year) appear less likely to have used preventive care and medical-based apps and, thus, mHealth in its current form appears to be a less effective health promotion tool for this demographic. This finding could be linked to challenges patients might be experiencing navigating some health apps. A recent study of low-income adults managing chronic diseases using mobile devices revealed that respondents could complete only $43 \%$ of all required tasks without assistance. ${ }^{22}$ In the study, patients were likely to report lack of confidence with the device and frustration with its design features and navigation components, ${ }^{22}$ and these elements might be linked to insufficient health literacy. ${ }^{23}$ It is therefore important to consider that initial motivation and sustained interest in using mobile health devices might be bolstered by technologists developing devices that integrate user literacy in design features, which can extend mHealth reach to more safety-net patients.

\section{Technology Reluctance of Low-Income Older Adults}

Our findings revealed gaps in mobile technology practices among low-income older adults. Though recent reports show an increase in digital health care technology use, from $14 \%$ to $67 \%$, among senior adults in the last decade, drivers of increased usage had higher incomes and advanced education. ${ }^{24}$ Furthermore, barriers to adoption and sustained use include lack of confidence in using electronic devices and physical disability limiting access..$^{25}$ Technologists might facilitate access by adapting technologies that support the unique physical and cognitive challenges of older-adult safety-net patients.

Additionally, given the rapid growth of technological developments, older adults will benefit when their primary care providers provide support for engaging in digital health care management. Though individuals over age 66 are likely to use health care systemsponsored websites if recommended by a health care provider, ${ }^{26}$ physicians are still slow to engage their patients in digital health care management. ${ }^{27,28}$ Providers have a unique opportunity to promote mHealth tools to their older-adult safety-net population, which may positively impact overall health outcomes.

\section{Persistent Gender Differences in Health Technology Engagement}

Women safety-net patients are consistently and significantly more likely to use mobile health technology for self-care management compared to men. Women are more likely to engage in preventive care (including weight management monitoring) and health care management (prescription refills, monitoring a health condition) using mobile apps. The gender difference in health-seeking behaviors is well-documented, ${ }^{29}$ but the disparity is more apparent when gender, race, and socioeconomic status (SES) are factors; differences in health-seeking behavior is of particular concern given the fact that ethnically and racially diverse low-SES men are more likely to report poor health status. ${ }^{30}$ Mobile health technology can make a difference, particularly for men who are hesitant about having regular face-to-face engagement with a health care provider. Interventional apps can target the health issues shown to be of primary concern among men (depression, substance abuse, anxiety), all of which are potential risk factors for long-term chronic health challenges. ${ }^{30}$

Additionally, research has presented the argument for "gender-specific medicine." which involves identifying the unique health care needs of men and women, including the biological and physiological 
factors that predict health care behaviors. ${ }^{31}$ Mobile health app developers must continue to tailor mobile apps to meet the specific needs of men and women, thus positively impacting the uptake of the innovation for both genders.

\section{Limitations and Strengths}

Two limitations of the study are the use of a niched population and possible selection bias. The study sampled CHC patients, which could limit generalizability of findings beyond this context. However, our study fills an important gap in existing knowledge since most investigations of digital health technology practices have largely targeted middleincome communities and ignored the populations represented in our sample. This is despite the fact that a substantial segment of the U.S. population does not have access to "traditional health services" and uses $\mathrm{CHCs}$ to address health care needs. Selection bias also could have occurred since the DC site used a convenience sample.

A prominent strength of the study is the fact that knowledge and practices were explored using a bicoastal sample. Information obtained about two geographically distinct patient groups enables the casting of a wider net in applying mobile health technologies to safety-net populations experiencing different vulnerabilities from disparate geographical contexts.

\section{CONCLUSIONS}

Low-resource safety-net patients demonstrated strong knowledge and initiated uptake of mobile health technologies. This finding is important because safetynet populations present with poor health outcomes, and digital health care tools can promote self-management and health care engagement. More work is needed to increase use among the lowest-income and olderadult safety-net patients so that the full health benefits that mHealth offers can be realized and health equity established for all patients. Part of the work might involve developing tools that simplify navigation and functionality for these two demographic groups. Additionally, research is needed to assess and predict sustained use of mobile health tools by low-resource communities, including factors affecting sustainability like cost of mobile applications.

\section{Patient-Friendly Recap}

- Low-income patients face substantial health challenges compared to the general population and are often served by safety-net community health centers.

- The authors surveyed community health center patients to ascertain their knowledge and use of mobile health technology.

- Respondents were aware of the value of mobile health tools to promote wellness and reported using smartphones and mobile apps for health care.

- Low-resource patient communities are capable of supporting clinical efforts to manage chronic disease via mobile technology.

\section{Acknowledgments}

The authors would like to thank the following people who made invaluable contributions to this project: students who helped to collect patient-level data at community health centers - Cindy Mendez Hernandez at Trinity Washington University; Tracie Warren, Jose Ramirez, Kimberly Smith Steik, and Julia Ward Bloomstine at Eastern Washington University; Salene M. Jones for data analytic input; our community partners in Washington, DC — staff and personnel at Casa Ruby, The Women's Collective and H.I.P.S.; and finally, our community partners in Washington State — Lisa Yohalem and the HealthPoint Research Council, physicians and staff at HealthPoint Bothell and HealthPoint Midway. We also would like to thank Kara Luckey of the University of Washington Tacoma Office of Research for editorial assistance.

\section{Author Contributions}

Study design: Laing. Data acquisition or analysis: Laing, Alsayid. Manuscript drafting: Laing. Critical revision: all authors.

\section{Conflicts of Interest}

None.

\section{Funding Source}

This study was funded by mini-grants awarded to Dr. Laing from Eastern Washington University (EWU). EWU had no role in study design, collection, analysis, and interpretation of data, the writing of the report, or the decision to submit the paper for publication.

\section{References}

1. Turner-Lee N, Smedley B, Miller J. Minorities, mobile broadband and the management of chronic diseases. Joint Center for Political and Economic Studies [Epub 2012 April 18]. http://jointcenter.org/research/minorities-mobilebroadband-and-management-chronic-diseases. Accessed September 15, 2017. 
2. World Health Organization. The MAPS (mHealth Assessment and Planning for Scale) Toolkit. Published September 2015. http:///www.who.int/reproductivehealth/publications/ mhealth/maps/en/. Accessed October 10, 2017.

3. Food and Drug Administration. Mobile medical applications: guidance for industry and Food and Drug Administration staff. U.S. Department of Health and Human Services [Epub 2015 Feb 9]. https://www.fda.gov/downloads/MedicalDevices/.../ UCM263366.pdf. Accessed October 9, 2017.

4. Fanning J, Mullen SP, McAuley E. Increasing physical activity with mobile devices: a meta-analysis. $J$ Med Internet Res. 2012;14(6):e161. CrossRef

5. Free C, Phillips G, Watson L, et al. The effectiveness of mobile-health technologies to improve health care service delivery processes: a systematic review and meta-analysis. PLoS Med. 2013;10(1):e1001363. CrossRef

6. Whittaker R, Borland R, Bullen C, Lin RB, McRobbie H, Rodgers A. Mobile phone-based interventions for smoking cessation. Cochrane Database Syst Rev. 2009;(4):CD006611. CrossRef

7. Liang X, Wang Q, Yang X, et al. Effect of mobile phone intervention for diabetes on glycaemic control: a metaanalysis. Diabet Med. 2011;28:455-63. CrossRef

8. Lim S, Kang SM, Shin H, et al. Improved glycemic control without hypoglycemia in elderly diabetic patients using the ubiquitous healthcare service, a new medical information system. Diabetes Care. 2011;34:308-13. CrossRef

9. Quinn CC, Shardell MD, Terrin ML, Barr EA, Ballew SH, Gruber-Baldini AL. Cluster-randomized trial of a mobile phone personalized behavioral intervention for blood glucose control. Diabetes Care. 2011;34:1934-42. CrossRef

10. Neumann CL, Menne J, Rieken EM, et al. Blood pressure telemonitoring is useful to achieve blood pressure control in inadequately treated patients with arterial hypertension. J Hum Hypertens. 2011;12:732-8. CrossRef

11. Rehman H, Kamal AK, Morris PB, Sayani S, Merchant AT, Virani SS. Mobile health (mHealth) technology for the management of hypertension and hyperlipidemia: slow start but loads of potential. Curr Atheroscler Rep. 2017;19(3):12. CrossRef

12. Birney AJ, Gunn R, Russell JK, Ary DV. MoodHacker mobile web app with email for adults to self-manage mildto-moderate depression: randomized controlled trial. JMIR Mhealth Uhealth. 2016;4(1):e8. CrossRef

13. Hall CS, Fottrell E, Wilkinson S, Byass P. Assessing the impact of mHealth interventions in low- and middle-income countries - what has been shown to work? Glob Health Action. 2014:7:25606. CrossRef

14. L'Engle K, Raney L, D'Adamo M. mHealth resources to strengthen health programs. Glob Health Sci Pract. 2014;2:130-1. CrossRef

15. Sondaal SF, Browne JL, Amoakoh-Coleman M, et al. Assessing the effect of mHealth interventions in improving maternal and neonatal care in low- and middle-income countries: a systematic review. PLoS One. 2016;11(5):e0154664. CrossRef

16. Jo Y, Labrique AB, Lefevre AE, et al. Using the lives saved tool (LiST) to model mHealth impact on neonatal survival in resourcelimited settings. PLoS One. 2014;9(7):e102224. CrossRef

17. Shin P, Alvarez C, Sharac J, et al. A profile of community health center patients: implications for policy. Henry J Kaiser Family Foundation [Epub 2013 Dec 23]. https://www.kff.org/ medicaid/issue-brief/a-profile-of-community-health-centerpatients-implications-for-policy/. Accessed October 23, 2017.
18. Rabi DM, Edwards AL, Southern DA, et al. Association of socio-economic status with diabetes prevalence and utilization of diabetes care services. BMC Health Serv Res. 2006;6:124. CrossRef

19. Raphael D, Farrell ES. Beyond medicine and lifestyle: addressing the societal determinants of cardiovascular disease in North America. Int J Health Care Qual Assur Inc Leadersh Health Serv. 2002;15(4):1-5. CrossRef

20. Rainie L, Perrin A. 10 facts about smartphones as the iPhone turns 10. Pew Research Center [Epub 2017 Jun 28]. http:// www.pewresearch.org/fact-tank/2017/06/28/10-facts-aboutsmartphones/. Accessed October 25, 2017.

21. Blue Shield of California Foundation. Improving the safetynet patient experience: 10 things health centers can do. (issue brief.) https://www.blueshieldcafoundation.org/sites/default/ files/BSCF_10_Things_IssueBrief_Final.pdf. Accessed November 6, 2017.

22. Sarkar U, Gourley GI, Lyles CR, et al. Usability of commercially available mobile applications for diverse patients. J Gen Intern Med. 2016;31:1417-26. CrossRef

23. Sarasohn-Kahn J. Digitizing the safety net: health tech opportunities for the underserved. California Health Care Foundation [Epub 2016 Feb 10]. http://www.chcf.org/publications/2016/02/ digitizing-safety-net. Accessed November 6, 2017.

24. Anderson M, Perrin A. Technology use among seniors. Pew Research Center. [Epub 2017 May 17.] http://www. pewinternet.org/2017/05/17/technology-use-among-seniors/. Accessed November 2, 2017.

25. Choi NG, DiNitto DM. The digital divide among low-income homebound older adults: Internet use patterns, eHealth literacy, and attitudes toward computer/Internet use. $J$ Med Internet Res. 2013;15(5):e93. CrossRef

26. Makovsky Health. Fifth annual "Pulse of Online Health" survey finds $66 \%$ of Americans eager to leverage digital tools to manage personal health. (news release dated February 24, 2015.) https://www.prnewswire.com/news-releases/fifthannual-pulse-of-online-health-survey-finds-66-of-americanseager-to-leverage-digital-tools-to-manage-personalhealth-300039986.html. Accessed November 6, 2017.

27. Broderick A, Haque F. Mobile health and patient engagement in the safety net: a survey of community health centers and clinics. The Commonwealth Fund [Epub 2015 May 13]. http://www.commonwealthfund.org/publications/issuebriefs/2015/may/mobile-health-and-patient-engagement-inthe-safety-net. Accessed October 25, 2017.

28. Bauer AM, Rue T, Keppel GA, Cole AM, Baldwin LM, Katon W. Use of mobile health (mHealth) tools by primary care patients in the WWAMI Region Practice and Research Network (WPRN). J Am Board Fam Med. 2014;27:780-8. CrossRef

29. Galdas PM, Cheater F, Marshall P. Men and health help-seeking behavior: literature review. $J A d v$ Nurs. 2005;49:616-23.

30. Williams DR. The health of men: structured inequalities and opportunities. Am J Public Health. 2003;93:724-31. CrossRef

31. Regitz-Zagrosek V. Sex and gender differences in health. EMBO Rep. 2012;13:596-603. CrossRef

(C) 2018 Aurora Health Care, Inc. 